\title{
XXVII. On the electric resistance of cobalt, iron, and nickel films in magnetic fields of various strengths
}

\author{
J. C. Beattie D.Sc. F.R.S.E.
}

To cite this article: J. C. Beattie D.Sc. F.R.S.E. (1898) XXVII. On the electric resistance of cobalt, iron, and nickel films in magnetic fields of various strengths, Philosophical Magazine Series 5, 45:274, 243-253, DOI: $10.1080 / 14786449808621130$

To link to this article: http://dx.doi.org/10.1080/14786449808621130

曲 Published online: 08 May 2009.

Submit your article to this journal $[\pi$

Џll Article views: 4

Q View related articles $\sqsubset$

4 Citing articles: 1 View citing articles 
XXVII. On the Electric Resistance of Cobalt, Iron, and Nickel Films in Magnetic Fields of various strengths. By J. C. Beattie, D.Sc., F.R.S,E.*

$\mathbf{T}$

$\mathrm{HE}$ fact that the paramagnetic metals iron, cobalt, and nickel have a different electric resistance according as the specimens examined are magnetized or not was first observed by Lord Kelvin. Attempts have be nl made to determine how the change in resistance is related to the magnetic properties of the specimen. Some have found that the variation is proportional to the maguetic moment; others, again, have found other relations. Certain it is that, in these three metals, the variation is an increase when the resistance is measured parallel to the lines of magnetic force, a decrease when perpendicular to them. In the following pages experiments will be described which had for their object the investigation of the relation of the resistance variation to the magnetization in films of cobalt, nickel, and iron transcersely magnetized. For such films, Knndt + bas shown that the Hall effect is proportional to the magnetization. The method employed in the experiments to be described in this paper, was to measure for any one film the Hall effect and the resistance perpendicular to the lines of magnetic force; then to compare these two effects at different field-strengths; and see whether or not any simple relation between the two existed. Did such a relation exist, we could then say in what manner the variation of resistance depended on the magnetization.

The films were deposited on platinized glass by electrolysis. Nickel was obtained from a solution of the double sulphate of nickel and ammonium; cobalt from the double sulphate of cobalt and ammonium; and iron from a solution of four parts of iron vitriol and three parts sal ammoniac in thirty parts water.

The specimens used were cut in the form of a rectangle usually $9 \mathrm{~mm}$. long by 7 or $8 \mathrm{~mm}$. broad; the thickness of the films varied from $\frac{1}{20,000}$ of a mm. to $\frac{1}{5,000}$ of a mm. Care was taken to have the thickness of each film as uniform as possible.

To measure the Hall effect the film had the usual two primary electrodes soldered along the whole extent of the ends, wires from a secondary battery of two cells were soldered

* Communicated by the Author, having been read before the Philosophical Society of South Africa, Nov. 24th, 1897.

+ Kundt, Wiedemann's Annalen, 1893. 
to these ; the current-which we shall call the primarycould be regulated by the insertion of resistances in the primary circuit. Two secondary electrodes were soldered on to two approxinately equipotential points lying on opposite sides of the film; these were joined to the galvanometer.

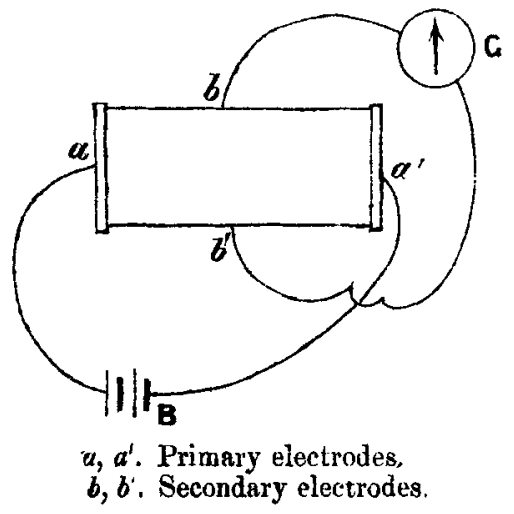

In those films where the secondary electrodes were not on the same equipotential line when there was no magnetic field, the electrodes could be brought to the same potential by

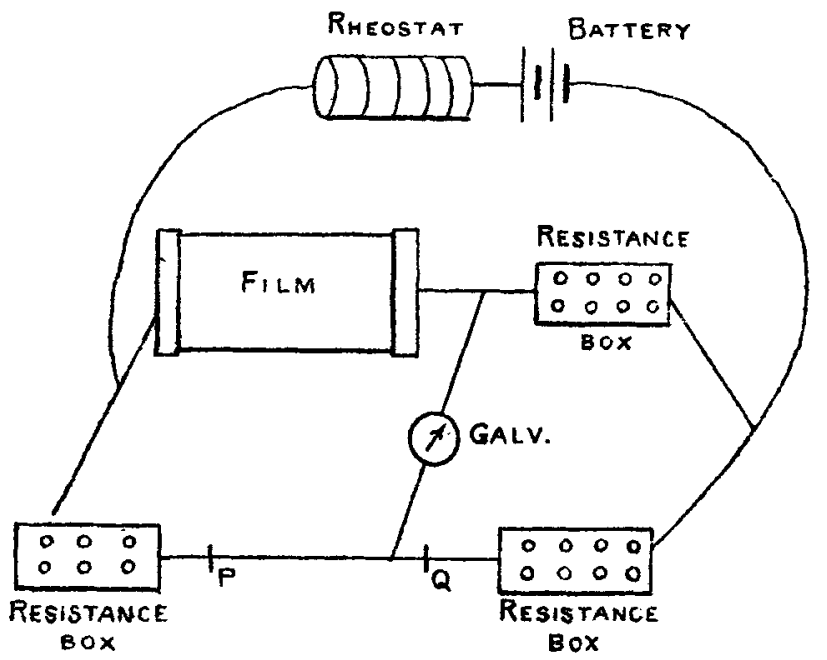

inserting a suitable resistance between one of the secondary electrodes and the properly chosen primary electrode.

To measure the variation of resistance the arrangement shown in the diagram was used. 
of Filns of Cobalt \&e. in Magnetic Fields.

The film formed one arm of a Wheatstone bridge with resistance-boxes in its other arms, and in addition a graduated german-silver wire, $P Q$, with a movable contact-maker. The current was supplied by the battery of two secondary cells already reterred to ; this current had to be very weakusually a few milliamperes-in order to avoid heating.

The resistances of the four arms of the britge were made as nearly equal as possible.

When a balance had been obtained in the Wheatstene bridge, the magnetic field was created ; the balance previously existing was disturbed, that is, a deflexion was now observed on the galvanometer due to the fact that the resistance of the film had changed. This reading was then assumed proportional to the current flowing through the galvanometer, that is proportional to $\Delta a$, the variation of the resistance, $a$, of the film. Such an assumption gives a result less than the true one by 0.003 of the total result in the most unfavourable case ; in other words, with a reading of $300 \mathrm{~mm}$. the error is $1 \mathrm{~mm}$.

The steady magnetic field was created by means of a small Ruhmkorff electromagnet with pole-pieces $10 \mathrm{~mm}$. in diameter and between 3 and $4 \mathrm{~mm}$. apart. The electromagnet with its pole-pieces was pierced through the centre so that the field-strength conld be determined by the rotation of the plane of polarization in a piece of glinss.

The galvanometer was placed in such a position as to be uninfluenced by the magnet. It had a resistance of $10 \mathrm{ohms.}$ Its scale was placed about 3 metres distant from its mirror.

The Hall effect is given in the results unly in scalereadings. The variation of resistance is given in scale-readings and in absolute measure.

To find what variation of resistance in the film was indicated by a galvanometer reading of one scale-division, the following method was employed. A suitable resistanceusually $100,000 \mathrm{ohms}$ - was placed in parallel with an arm of the bridge; the point on the graduated scale which was such as to give no current through the galvanometer was found when the parallel circuit of 100,000 obms was broken; this latter was then made and the reading observed. Evidently, knowing the resistance of the arm of the bridge concerned, of the shunt, and knowing the deflexion produced, the variation of resistance represented by one scale-division defiexion on the galvanometer conld be calculated.

A plus sign denotes an increase, a minus sign a decrease of resistance.

In most of the films the Hall effect was observed first; 
then the variation of resistance. The order in which the two are mensured affects the result in the case of nickel ; in that metal there is a hysteresis effect in both phenomena. In cobalt the hysteresis effect is so small as to be negligible.

To discover whether or not the resistance of the platinized giass and the connecting wires was modified by the presence of the magnetic field, a nickel film was first used; its variation of resistance was observed and the nickel afterwards taken off by means of acid; the platinum mirror and its connecting wires showed no change of resistance due to the creation of the magnetic field.

\section{Cobalt.}

The following are some of the results obtained with cobalt films :-

No. XXIII.--Resistance between primary electrodes $2 \cdot 492 \Omega$. Primary current ${ }_{300}^{4} \mathrm{amp} . \quad\left(8 \frac{3}{4} \times 13 \frac{1}{2} \mathrm{~mm}.\right)$

\begin{tabular}{|c|c|c|c|c|}
\hline $\begin{array}{l}\text { Field in } \\
\text { C.G.S. units. }\end{array}$ & Hall effect. & $\begin{array}{l}\text { Variation of } \\
\text { resistance. }\end{array}$ & $\frac{\text { Hull effect }}{\sqrt{\text { variation. }}}$ & $\frac{R_{1}-R}{R}$ \\
\hline $\begin{array}{r}2,400 \\
\mathbf{5}, 100 \\
6,600 \\
8,500 \\
10,300 \\
11,700 \\
13,800 \\
16,160\end{array}$ & $\begin{array}{l}37 \cdot 75 \\
58 \cdot 00 \\
85 \cdot 75 \\
117 \cdot 75 \\
135 \cdot 75 \\
154 \cdot 5 \\
163 \cdot 75 \\
168 \cdot 00\end{array}$ & $\begin{array}{c}-13.75 \\
-350 \\
-86.25 \\
-1305 \\
-1790 \\
-229.5 \\
-2430 \\
-256.5\end{array}$ & $\begin{array}{l}10 \cdot 2 \\
10 \cdot 2 \\
10 \cdot 5 \\
10 \cdot 3 \\
10 \cdot 1 \\
10 \cdot 2 \\
10.5 \\
10.5 \\
10.3\end{array}$ & $\begin{array}{l}-0.0003644 \\
-0.0009275 \\
-0.001756 \\
-0.002458 \\
-0.004744 \\
-0.006082 \\
-0.006440 \\
-0.006796\end{array}$ \\
\hline
\end{tabular}

No. XXVI.-Resistance between primary electrodes $2 \cdot 019 \Omega$. Primary current $5 \frac{4}{500}$ amp. $\left(9 \frac{3}{4} \times 7 \frac{1}{4} \mathrm{~mm}.\right)$

\begin{tabular}{|c|c|c|c|c|}
\hline $\begin{array}{l}\text { Field in } \\
\text { c.G.S. units. }\end{array}$ & Hall effect. & $\begin{array}{c}\text { Variation of } \\
\text { resistance. }\end{array}$ & $\frac{\text { Hall effeet }}{\sqrt{\text { variation }}}$ & $\frac{\mathbf{R},-\mathbf{R}}{\mathbf{R}}$. \\
\hline $\begin{array}{r}4,300 \\
5,400 \\
8,520 \\
10,300 \\
11,700 \\
13,800 \\
16,160\end{array}$ & $\begin{array}{l}46 \cdot 25 \\
73 \cdot 0 \\
114 \cdot 5 \\
135-25 \\
167 \cdot 0 \\
183: 5 \\
188 \cdot 0\end{array}$ & $\begin{array}{l}-190 \\
-34.5 \\
-1040 \\
-135.75 \\
-183.5 \\
-208.0 \\
-2250\end{array}$ & $\begin{array}{l}11.0 \\
12.3 \\
11 \cdot 2 \\
116 \\
129 \\
12.6 \\
12.5 \\
12.0\end{array}$ & $\begin{array}{l}-0000699 \\
-0001269 \\
-0.003827 \\
-0.004968 \\
-0.006726 \\
-0007654 \\
-0.008290\end{array}$ \\
\hline
\end{tabular}


The films XXIII. and XXVI. were deposited trom a solution of the double salt of cobalt and ammonium; another film was then made from a rosee-cobalt chloride solution. With it the following results were obtained.

No. XXXI.-Resistance between primary electrodes $4 \Omega$. P'rimary current $\frac{4}{30}$ amp. (Size $10 \times 7 \mathrm{~mm}$.)

\begin{tabular}{|c|c|c|c|c|}
\hline Field. & Hall effect. & $\begin{array}{l}\text { Variation of } \\
\text { resistance. }\end{array}$ & Hall effect & $\frac{\mathbf{R}_{1}-\mathbf{R}}{\mathbf{R}}$. \\
\hline $\begin{array}{r}2,500 \\
4,370 \\
5,590 \\
8,560 \\
11,360 \\
14,070 \\
16,275\end{array}$ & $\begin{array}{r}30 \cdot 0 \\
53 \cdot 5 \\
69 \cdot 5 \\
105 \cdot 0 \\
129 \cdot 5 \\
145 \cdot 0 \\
152 \cdot 0\end{array}$ & $\begin{array}{c}26 \cdot 25 \\
43.60 \\
95 \cdot 0 \\
137.0 \\
155 \cdot 0 \\
1710\end{array}$ & $\begin{array}{l}10.3 \\
10.6 \\
10.5 \\
11.0 \\
11 \cdot 6 \\
11 \cdot 6 \\
10.9\end{array}$ & $\begin{array}{l}-0.000355 \\
-0.000592 \\
-0.001287 \\
-0.001851 \\
-0002100 \\
-0.002317\end{array}$ \\
\hline
\end{tabular}

Other mirrors were used; some of the results are given in the appended graph. The form of the curve is the same in all. We have first a parabolic part starting at the origin and continuing up to a field-strength of about 9000 units; the form then undergoes a change, and finally the concave part is turned towards the axis. This form and the fact that the Hall effect divided by the square root of the change of resistance is constant justifies the conclusion that in cobalt the difference in the resistance of a thin film of it when transversely magnetized from its resistance when unmagnetized is proportional to the magnetization squared.

The value of this variation differs very much in different mirrors. This can best be seen from the curves, which are drawn to the same scale. No hysteresis effect was observed, although in the Hall effect a slight effect was obtained. 
248 Dr. J. C. Beative on the Electric Resistance

Variation of Resistance in Cobalt.

External Field.

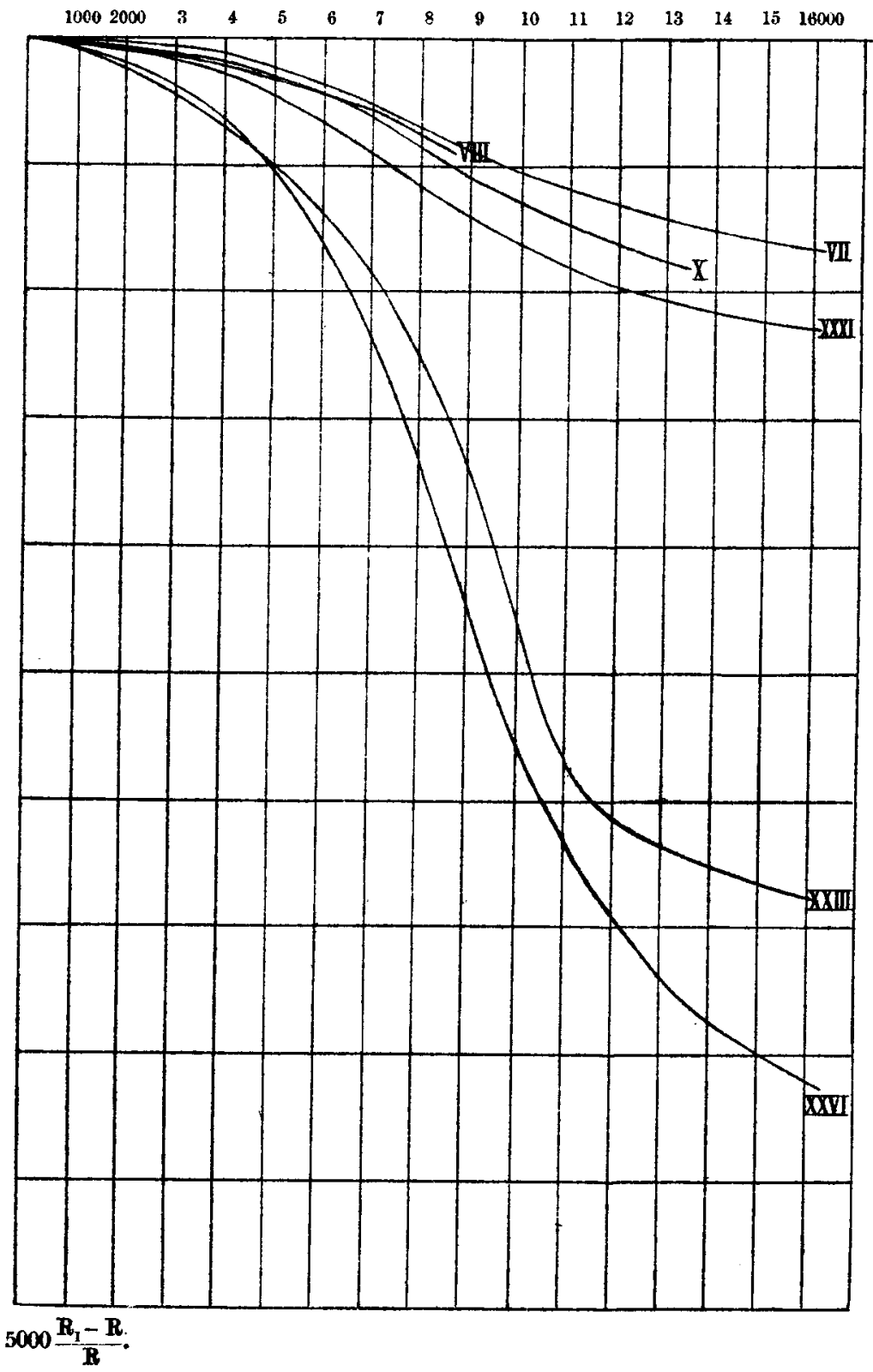


Nickel Films.

The results obtained with nickel differed very much for different plates both qualitatively and quantitatively. The results were also much complicated by a very great hysteresis effect in the variation of resistance ; this caused a greater variation in the film's resistance after it had been magnetized and demagnetized several times.

For example, with film XXVII. the following results were obtained.

No. XXVII. First time used. $\left(13 \frac{1}{2} \times 8 \frac{3}{4} \mathrm{~mm}\right.$. $)$

\begin{tabular}{|c|c|c|c|}
\hline Field. & $\begin{array}{l}\text { Hall effect } \\
\text { in millinn. }\end{array}$ & $\begin{array}{l}\text { Variation of } \\
\text { resistance in } \\
\text { nillim. }\end{array}$ & $\frac{\text { Hall effect }}{\sqrt{\text { variation }}}$ \\
\hline $\begin{array}{r}2,620 \\
4,370 \\
5,590 \\
8,560 \\
11,360 \\
14,070 \\
16,000\end{array}$ & $\begin{array}{l}152 \cdot 25 \\
216 \cdot 0 \\
228 \cdot 1 \\
234 \cdot 5 \\
241 \cdot 25 \\
242 \cdot 75 \\
245 \cdot 5\end{array}$ & $\begin{array}{r}-50.0 \\
-90.0 \\
-104.5 \\
-116.7 \\
-123.0 \\
-1250 \\
-1340\end{array}$ & $\begin{array}{l}21 \cdot 4 \\
22 \cdot 7 \\
22 \cdot 3 \\
21 \cdot 7 \\
21 \cdot 7 \\
21 \cdot 6 \\
21 \cdot 2 \\
21 \cdot 8\end{array}$ \\
\hline \multicolumn{4}{|c|}{ Second time used. } \\
\hline $\begin{array}{r}2,000 \\
2,620 \\
4,370 \\
5,590 \\
8,560 \\
11,360 \\
14,070 \\
16,000\end{array}$ & $\begin{array}{l}111 \cdot 0 \\
152 \cdot 25 \\
216 \cdot 0 \\
228 \cdot 4 \\
231 \cdot 5 \\
241 \cdot 25 \\
242 \cdot 75 \\
2455\end{array}$ & $\begin{array}{l}-45 \cdot 5 \\
-86 \cdot 0 \\
-192 \cdot 2 \\
-253 \cdot 0 \\
-316 \cdot 0 \\
-347 \cdot 0 \\
-370 \cdot 0 \\
-388.5\end{array}$ & $\begin{array}{l}16 \cdot 4 \\
16 \cdot 4 \\
15 \cdot 5 \\
14 \cdot 4 \\
13 \cdot 1 \\
129 \\
126 \\
12 \cdot 4\end{array}$ \\
\hline
\end{tabular}

A great number of other films behaved in the same manner as XXVII. The results for some of them are given in the eurves on page 250 .

It will be noticed that the form of the curve is first parabolic, with the convex side towards the horizontal axis; that there is a point of inflexion usually between a field-strength of 5000 and 6000 C.G.S. units; and that after that strength the concave part of the curve is turned towards the horizontal axis. Roughly this is the same thing that we had with cobalt; but here we have not usually a constant quantity when the Hall effect is divided by the square root of the resistance variation. The difference between the resistance variation and the Hall effect squared is shown for film XIV. in the graph on page 251. 


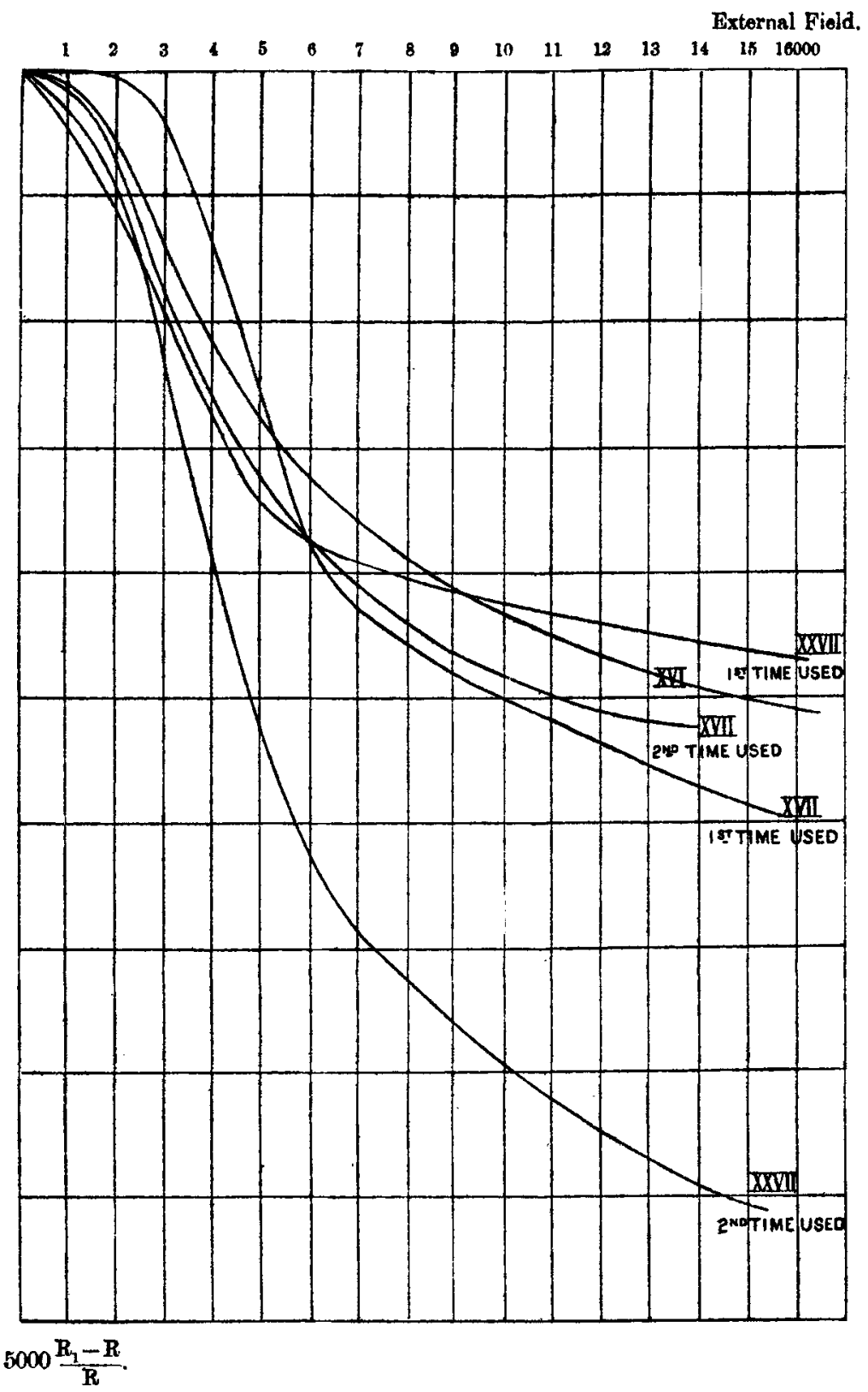


Fxtemal Field.

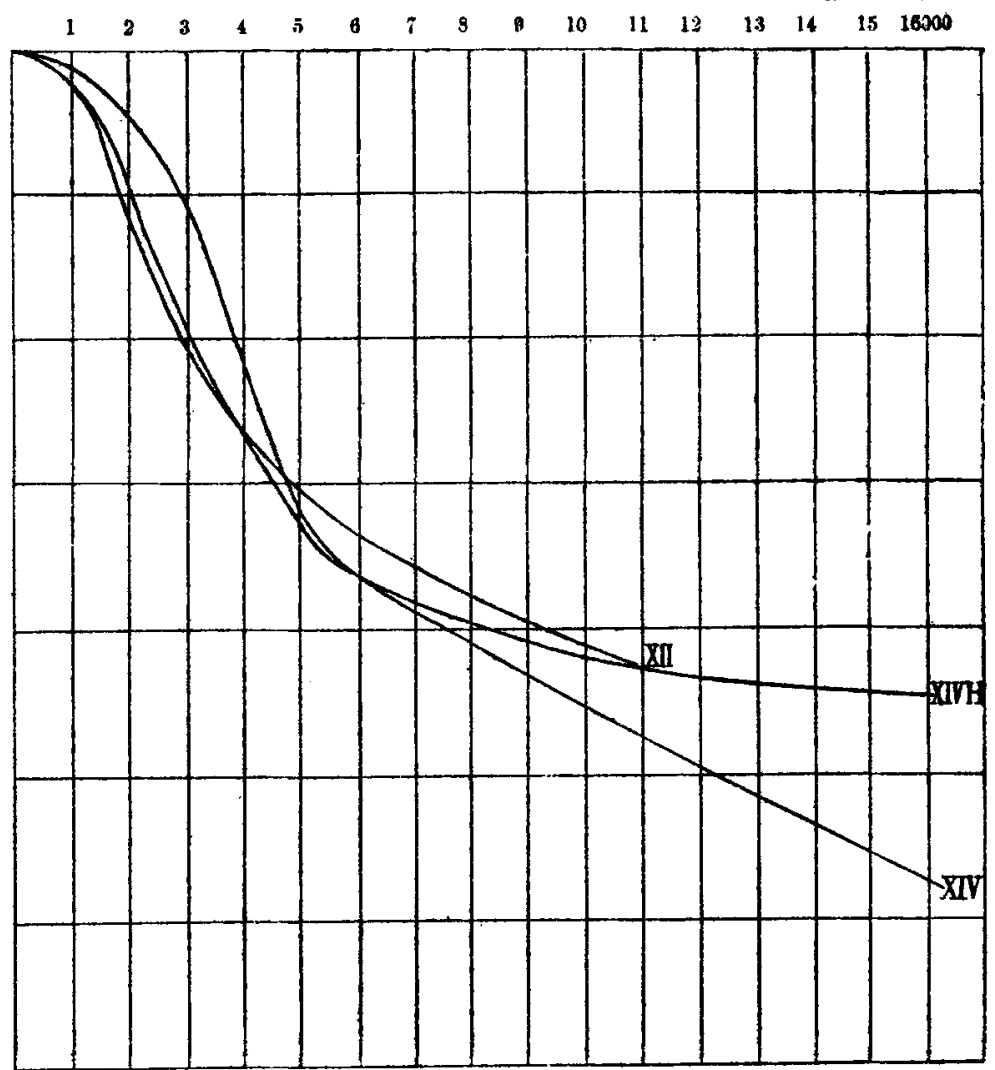

$5000 \frac{R_{1}-R}{R} \quad$ XIV. H. - Hall effect squared for No. XIV.

Finally, in some films it was found that the resistance variation was for low fields an increase, and for bigher fields a decrease. The results for three films of this nature are shown in the following diagram:- 
252 On the Electric Resistance of Films of Cobalt \&c.

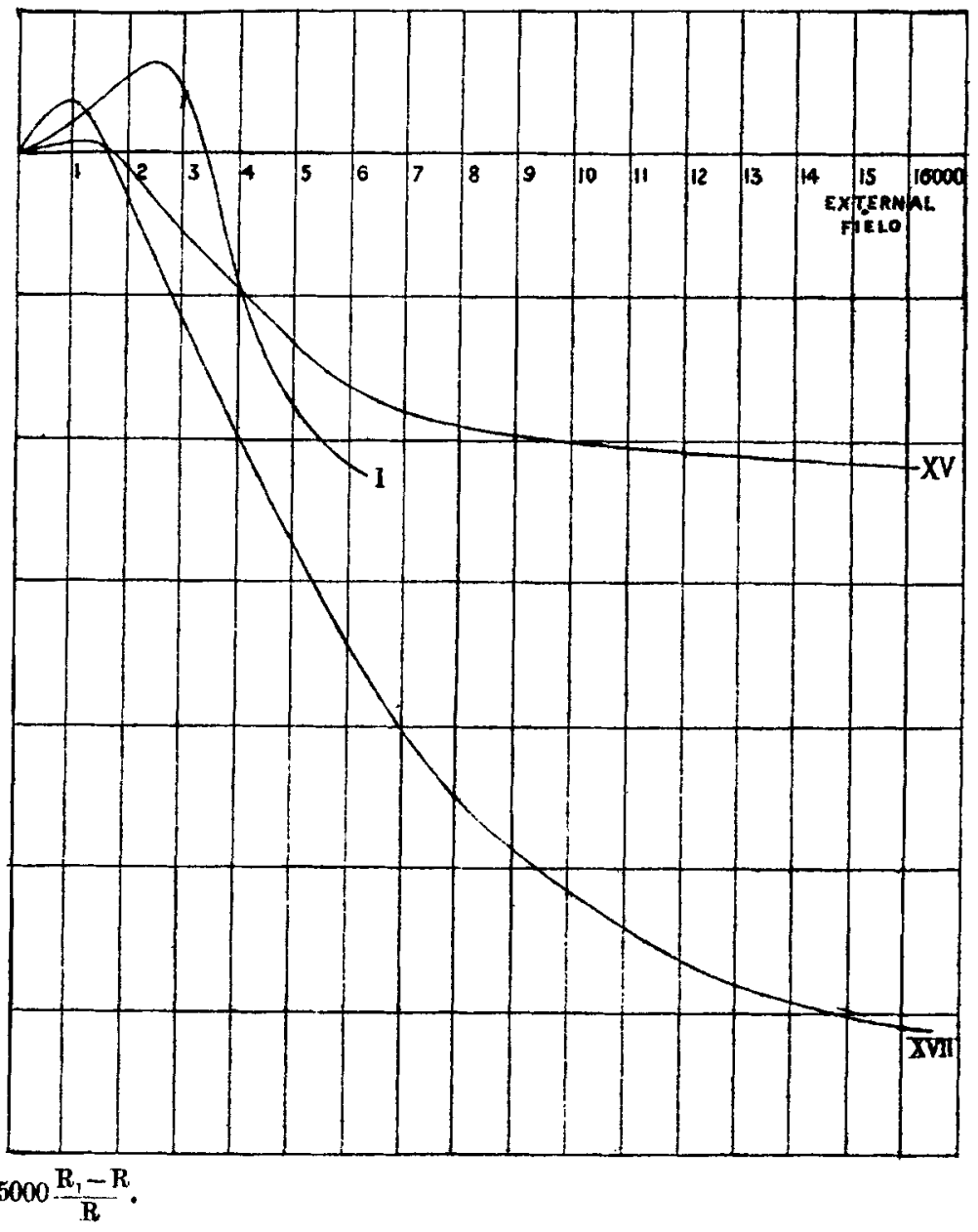

Iron.

In the iron films tlie variation of resistance with fields up to 16,000 C.G.S. units due to transverse magnetization was so small that even in the most favourable ease not more thyn 30 scale-divisions' reading could be observed on the galvanometer-scale. So far as conclusions from such sliglit effects could be relied upon, it appeared as if the resistance variation was not proportional to the magnetization squared.

\section{Conclutsions.}

(1) Films of nickel, cobalt, and iron show a change in ibeir electrical resistance when brought into a sufficiently strong 
magnetic field so as to be transversely magnetized. This variation is greatest in nickel and in cobalt, and least in iron; the variation can be observed in nickel at much lower fields than in cobalt, in some cases with a strength of 1000 C.G.S. units: in cobalt it can be with certainty observed from 2000 U.G.S. units onwards. In iron the variation can usually not be observed with fields weaker than 6000 C.G.S. units.

(2) In cobalt films a direct relation exists between the variation of the resistance and the. Hall effect: from it we conclude that the latter is proportional to the magnetization squared.

(3) In nickel the variation of resistance differs very considerably according to the specimen used. In all the mirrors, however, it shows signs of attaining a maxinum, but at a higher field than that required for the Hall effect maximum.

Again, the variation becomes greater in some plates after they have been used, so that a plate which originally had a resistance variation proportional to the magnetization squared has, after first being used, a higher variation than this relation would lead us to expect.

(4) In iron the variation of resistance is less than proportionality to magnetization squared would lead $u s$ to expect.

I have to express my thanks to Professors Warburg and Rubens for their great kindness and assistance to me while engaged in carrying out the above experiments.

South African College, Capetown, December 1897.

XXVIII. On the Determination of the Conductivity of Liquids in Thin Layers. By G. B: BryaN, B.Sc., 1851 Exhibition Science Scholar, University College, Nottingham, St. John's College, Cambridge*.

\section{INTRODUCTION.}

TNTEREST in this subject has been aroused by the work of Koller $\dagger$, who found that, with certain liquids, the conductivity decreased as the thickness of the layer was decreased; and it was suggested by Prof. J. J. Thomson that it might be worth while repeating some of Koller's experiments. In doing this the apparatus and method of measuring the resistance differed from Koller's, and therefore his method of experimenting will be briefly described.

To obtain a thin layer of a liquid, Koller took two flat circular metal plates, and placed one horizontally on the bottom of a glass vessel; the other was laid on this and

* Communicated by Prof. J. J. Thomson, F.R.S.

$\dagger$ Wien. Ber. 98 ii. $a$, p. 201 (1889).

Phil. Mrag. S. 5. Vol. 45. No. 274. March 1898. 